\title{
Hipótesis higienista
}

\section{The hygienist hypothesis}

Andrés Fabián Velasco Oliveros, MD.(1); Sergio Díaz Martínez, MD.(1); Robin Rada Escobar, MD.(2)

\section{RESUMEN}

La hipótesis higienista sugiere que los cambios medioambientales en el mundo industrializado han hecho que se reduzca el contacto microbiano a una edad temprana, lo cual conduce al aumento de enfermedades alérgicas como el eccema atípico, la rinoconjuntivitis alérgica, el asma (1), la dermatitis atópica y la gastroenteropatía alérgica $(2,3)$. En los noventa, los hallazgos epidemiológicos se combinaron con el paradigma Th1/ Th2 de la respuesta inmune (4) para proveer una teoría coherente. Recientes avances en Epidemiología, Inmunología y Genética son la columna vertebral de esta hipótesis.

Palabras clave: genética, medio ambiente, respuesta inmune, alergia.

\section{ABSTRACT}

The hygienist hypothesis suggests that environmental changes in the industrialized world have reduced exposure to microbes at early ages, thus increasing allergic diseases such as atopic eczema, allergic rhinoconjuntivitis, asthma (1), atopic dermatitis, and allergic gastroenteropathy (2,3). In the 1990s, epidemiologic findings were combined with the Th1/Th2 paradigm of immune response (4) to provide a coherent theory. Recent advancements in epidemiology, immunology, and genetics are the mainstay of this hypothesis.

Key words: genetics, environment, immune response, allergy.

Rev Colomb Neumol 2011; 23 (3): 73-79.

\section{HISTORIA}

La hipótesis higienista fue propuesta en 1989 por Strachan (5), en parte para explicar el incremento de la prevalencia de las condiciones atópicas (aumento de inmunoglobulina IgE, predisponente en estados alérgicos) (22). La idea se originó de observaciones epidemiológicas que sugerían una correlación inversa entre el tamaño de la familia y al prevalencia de la rinitis alérgica, llevando a una hipótesis general que planteaba que la infección adquirida por los hermanos mayores en la edad temprana, podría conferir protección contra el desarrollo de enfermedades atópicas como el eccema, la rinoconjuntivitis alérgica y el asma (1).
El paradigma Th1/Th2 de la respuesta inmune adaptativa, fue el primer soporte para la hipótesis higienista. Éste tuvo como principio que las células T indiferenciadas se pueden "polarizar" hacía un subtipo Th1 gracias a un estímulo de citoquinas tipo INF- $\gamma$ (interferón gamma), o hacia un subtipo Th2, por un estímulo de citoquinas tipo IL-4 (interleucina 4); esta diferenciación hace que cada subtipo de célula produzca un patrón distinto de citoquinas (Figura 1); hoy día se han descubierto otros dos subtipos (Th0 y Th3). Este paradigma se unió a la hipótesis higienista, dado que los individuos atópicos (con mayor predisposición a las enfermedades alérgicas) presentaban una respuesta tipo Th2 muy exacerbada, al igual que individuos con enfermedades autoinmunes

(1) Médico Universidad Militar Nueva Granada, Hospital Militar Central, Bogotá.

(2) Internista Neumólogo Jefe Servicio de Medicina Interna, Hospital Militar Central. Bogotá, Colombia.

Correspondencia: sandresfa@yahoo.es - robinrada1@hotmail.com

Recibido: septiembre 20 de 2011. Aceptado: octubre 5 de 2011. 
presentaban una respuesta tipo Th1 exagerada, pero eso va más allá de lo que atañe a esta revisión.

\section{FACTORES AMBIENTALES}

La relación inversa entre la incidencia de enfermedades infecciosas y enfermedades alérgicas, se ha estudiado en niños de granja . y se ha encontrado que el crecer en esos sitios confiere una protección importante contra el desarrollo de la atopia $(6,8)$. Análisis más detallados de estos estudios mostraron que el factor que mejor explicaba la diferencia de la prevalencia de las alergias en niños que vivían en las granjas y aquellos que habitaban en la misma ciudad pero no en granjas, era el hecho de tener contacto con ganado y aves de corral $(2,6)$. Estos resultados sugerían que sustancias producidas por animales de granja, las cuales podrían estar en mayor concentración en establos cerrados, podrían desempeñar un rol importante en la prevención de las alergias. En un estudio de Von Mutius y colaboradores (7), en el cual se analizó polvo recogido de granjas donde vivían niños, se mostraron niveles marcadamente altos de endotoxina en comparación con las casas de niños que vivían en la misma área rural, pero no en granjas. Las endotoxinas son lipopolisacáridos (LPS) constitutivos de la pared celular de las bacterias Gram negativas que potencian una respuesta de tipo Th1. Los niveles de endotoxina varían extensamente, pero tienden a ser altos en ambientes donde hay animales de granja como vacas, caballos, y cerdos, dado que la mayor fuente de endotoxina es la flora fecal de mamíferos grandes. La endotoxina también se encuentra en el polvo de las casas, al aire libre y en la suciedad, y sus cantidades pueden ser medidas en polvo o aire.

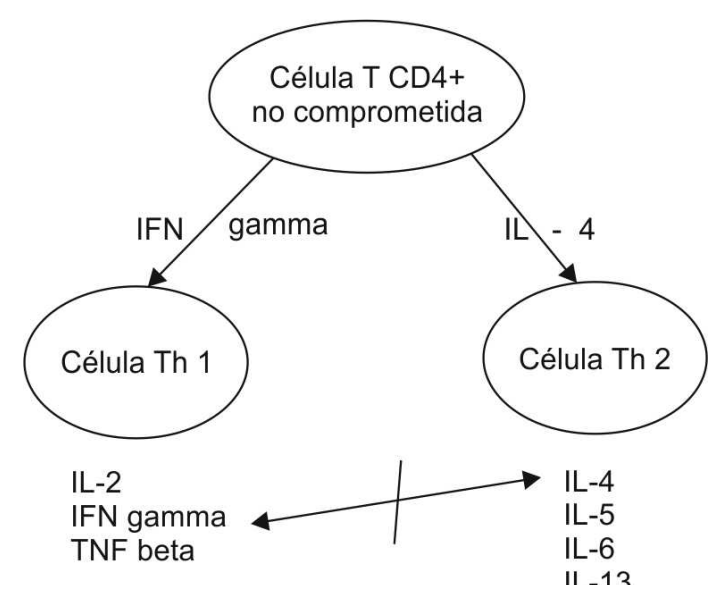

Figura 1. Diferenciación de las células T CD4. Tomada de: Stephen J. Immunocompetence and Allergy. Pediatrics 2004; 113 (4): 1107-13.
En su forma de transporte aéreo, la endotoxina puede ser inhalada o deglutida, actuando como una potente molécula inmunoestimuladora a través de su lípido A (9), el cual es reconocido por el receptor CD14, el toll-like receptor 4 (TLR4) y otras moléculas (MyD88 y TLR9) (3), con la consecuente síntesis de citoquinas por la célula receptora.

Los efectos de la endotoxina son dosis- dependiente; en altas dosis, la endotoxina produce una neumonitis por hipersensibilidad y estimula la liberación de mediadores inflamatorios. Incluso en dosis bajas, la endotoxina se asocia con cuadro asmático durante el primer año de vida.

Más allá de la dosis, si la exposición a la endotoxina es protectora o perjudicial, probablemente depende de una mezcla compleja entre distribución geográfica, exposición durante el ciclo de vida, cofactores ambientales y genética.

Tanto en modelos animales como en estudios en humanos, la exposición a la endotoxina temprano en la vida, durante el desarrollo del sistema inmunológico, parece ser el factor más importante en la protección que provee contra el desarrollo de enfermedad alérgica (3).

Al igual que la exposición a este componente bacteriano, también se han hecho estudios que demuestran que los agentes virales a una edad temprana también participan en la protección contra un fenotipo atópico. Un ejemplo de ello es el sarampión; en estudios se ha visto que la infección por este virus reduce el grado de sensibilización, aunque por otro lado, niños con una predisposición atópica exhiben una mortalidad mayor a causa de éste (1).

Algo similar sucede con el VSR (virus sincitial respiratorio); se especula que la bronquiolitis producida por este virus en una edad temprana, guarda relación con un mayor riesgo de desarrollar signos asmáticos en la vida adulta. Sin embargo no está claro si la infección por el VSR conlleva a atopia o si infantes que desarrollan este estado atópico cursan con manifestaciones más severas durante la infección por el VSR (1).

\section{ALERGENOS Y ATOPIA}

Existe abundante evidencia que prueba, que la exposición a altos niveles de alergenos temprano en la vida, es la causa que más contribuye al desarrollo de un fenotipo atópico, dado que la sensibilización atópica está fuertemente asociada con un cuadro asmático persistente en el niño. Por esta razón, sería de gran utilidad determinar los niveles críticos de exposición en 
el ambiente, para que dicha sensibilización no ocurra. Se sabe que la sensibilización a alergenos específicos refleja un nivel muy similar de éstos encontrados en las casas. En muchas comunidades, el principal alergeno en las casas es el polvo de ácaro $(2,11)$, pero en casas donde este polvo de garrapata es raro, como en climas secos o grandes alturas, los alergenos principales son las emanaciones de perros y gatos.

En las ciudades interiores de los Estados Unidos, en casas de personas de bajos ingresos, el alergeno que más a menudo sensibiliza a sus habitantes procede de cucarachas alemanas (2). Por las distintas propiedades de los alergenos es difícil definir una dosis que sea el punto de referencia donde empieza la sensibilización, aunque hoy en día se han empleado técnicas para su medida dependiendo del alergeno a estudiar. Los alergenos derivados de polvo de ácaro (designados Der pl para unas especies de ácaro y Der fl para otras) y cucarachas alemanas (Bla gl) se encuentran en partículas pesadas, que son las mejores cuantificadas en el polvo de casa, y la cantidad se expresa como microgramos de alérgeno por gramo de polvo de casa (2). En contraste, las emanaciones de animales domésticos son transportadas por vía aérea en partículas de $\mu 5 \mathrm{~m}$ o más pequeñas, y su nivel de exposición podría medirse mejor mediante técnicas de prueba de aire (2).

\section{INMUNOLOGÍA}

Las diferentes etiologías [bacteriana (1-3, 6-8), viral o parasitaria (1)] que encierra la hipótesis higienista, tienen como fundamentación las posibles respuestas que éstas generan en el sistema inmune del hospedero y así la forma de generar un balance entre Th1 y Th2 o en su defecto una posible polarización a alguna de estas dos respuestas, teniendo en cuenta que esta polarizacion estará dada por los diferentes estímulos antigénicos a los que esté expuesta la persona, sobretodo en la infancia en un periodo llamado "ventana crítica" que comprende del segundo al décimo segundo mes de edad (1), cuando el sistema inmune del niño está en desarrollo (Figura 2).

Es de suprema importancia mencionar que hoy por hoy se conoce que los infantes al nacer tienen una predilección hacia una respuesta Th2, posiblemente porque es una forma de protección contra un rechazo materno $(1,2,12)$.

\section{BACTERIANA}

La inmunología de la respuesta inmune contra mecanismos bacterianos extracelulares está dada por una interacción de dos vías: células B, encargadas de la producción de anticuerpos, y APC (célula presentadora de antígenos), encargadas de la presentación antigénica a las células $\mathrm{T}$, las cuales producen una respuesta de tipo Th1 para la activación de macrófagos a fin de poder fagocitar y destruir las bacterias extracelulares (10).

Por otro lado, las bacterias intracelulares despiertan una inmunidad innata que depende de los fagocitos y de las células NK (natural killer), y una inmunidad adaptativa, a cargo de las células TCD4 y TCD8, que mediante citoquinas Th1 activan macrófagos para la destrucción de la célula afectada (10).

Este tipo de respuesta tiene un papel importante en la hipótesis higienista ya que la polarización a Th1 se asocia con un fenotipo saludable (no atópico), y una polarización a Th2 a uno atópico. Se ha encontrado que la estructura bacteriana más relacionada con la polarización a Th1, y por consiguiente con un papel inmunizador contra la atopia, es el LPS (1-3, 6-8), componente de la pared de las bacterias Gram negativas; esto indica que un posible tratamiento temprano contra un fenotipo atópico podría estar en las manos de investigaciones con este tipo de bacterias.

El sistema inmune innato está capacitado para distinguir antígenos microbianos entre millares de antígenos medioambientales, a través de moléculas como los toll like receptors (TLRs) y CD14 $(1,3)$, los cuales reconocen moléculas conservadas asociadas a patógenos, incluyendo las regiones $\mathrm{CpG}$ no metiladas, características del DNA y LPS bacterianos. El reconocimiento de las regiones CpG bacterianas por medio del TLR9 induce una respuesta inmunológica de tipo Th1.

EI LPS bacteriano es un poderoso inductor de la respuesta inmune innata vía TLR2 y TLR4 $(1,3)$. CD14 parece tener una función esencial como correceptor

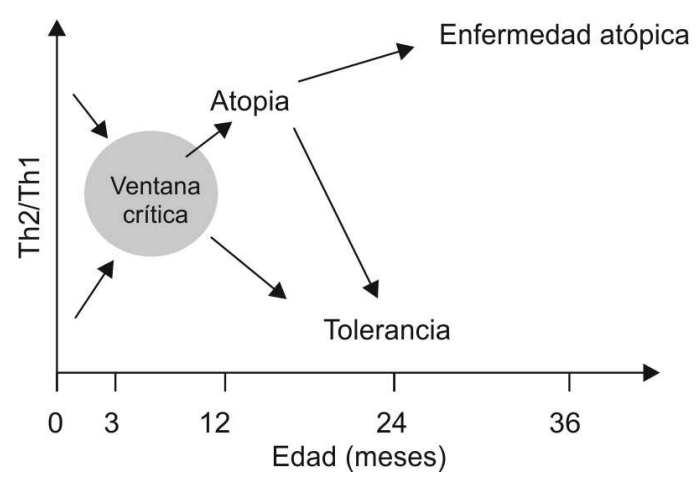

Figura 2. Desarrollo de la respuesta inmune en infantes sanos y atópicos. Tomada de: Rautava S, et al. The hygiene hypothesis of atopic disease-an extended version. J Pediatric Gastroenterol and Nutrition 2004; 38: 378-88. 
para el LPS, pero además de este componente, también reconoce el peptidoglicano, una estructura universal que compone la membrana celular bacteriana (1).

La activación del sistema inmune por parte de bacterias, a través de los TLR, está mediada por la inducción del factor de trascripción NF-kB (1), siendo éste el encargado de dar la señal de traducción proteica para generar las respectivas citoquinas.

Pero ¿por qué la instauración de la flora normal intestinal en los primeros meses de vida, que generalmente es por bacterias, no conlleva una protección contra un fenotipo atópico? Se parte de la primicia de que los microorganismos de la flora normal no son patógenos, y dado el caso que lo fueran, no serían flora normal. Se ha observado que la mayoría de microorganismos de la flora normal son capaces de producir un efecto inmunomodulador, inhibiendo la activación del factor NF-kB (1). Por otro lado, algunos microorganismos que forman parte de esta flora normal, como Lactobacillus rhamnosus (Lactobacillus GG) con propiedades probióticas, tienen la capacidad de activar la vía NF-kB, en una forma similar al Streptococcus pyogenes (1), un patógeno virulento, indicando que algunos miembros de la flora intestinal normal proveen señales inmunomoduladoras importantes en la polarización Th1.

La nomenclatura reciente de las células T presentes en la mucosa, hace referencia a un tercer grupo de células $T$, llamadas células $T$ reguladoras $(\operatorname{Tr} 1)$ o células Th3, las cuales se encargan de secretar TGF-ß (Factor transformante de crecimiento beta), del cual se han demostrado efectos como:

a) Supresor sobre células TH1 y Th2 $(1,6)$.

b) Implicación en la protección contra la enfermedad autoinmune de tipo Th1.

c) Potencial inmunomodulatorio de la flora intestinal como mediador de enfermedad atópica (Figura 3).

d) Inductor de una adecuada producción de $\lg A$ por parte de las células $B$, manteniendo la función protectora de la mucosa intestinal (1).

Datos recientes indican que el TGF- $\beta$ y la IL-10 son las citoquinas más importantes al mediar un efecto regulador. Además éstas parecen actuar de un modo sinergista; TGF- $\beta$ favorece la producción de IL-10, siendo ésta considerada como el promotor central de la tolerancia hacia la flora normal intestinal (1). Por consiguiente, un defecto en la producción de IL-10, reflejado en concentraciones disminuidas de esta citoquina en el intestino, podría tener un rol en la patogénesis de enfermedad intestinal inflamatoria. Por el contrario, una predominancia de IL-10 en el intestino, puede considerarse como un sello de un tracto respiratorio sano (1).

\section{VIRAL}

Desde el punto vista inmunológico la respuesta contra virus se divide en dos tipos:

a. Respuesta innata: la cual comprende la inhibición de la infección por parte de los INF de tipo I y la destrucción de las células infectadas a cargo de las células NK.

b. Respuesta adaptativa: comprende anticuerpos neutralizantes, células T CD8 (la secreción de INF potencia su actividad citotóxica) (10).

Como se mencionó anteriormente, existen varios virus que se han mencionado como candidatos en la hipótesis higienista, entre éstos sarampión y el VSR, con disminución y aumento a la sensibilización atópica respectivamente, cuando existe infección por éstos (1). Sin embargo, no se ha esclarecido en su totalidad el papel que éstos desempeñan en la hipótesis higienista ya que ha habido resultados contradictorios en distintos tipos de estudios (1).

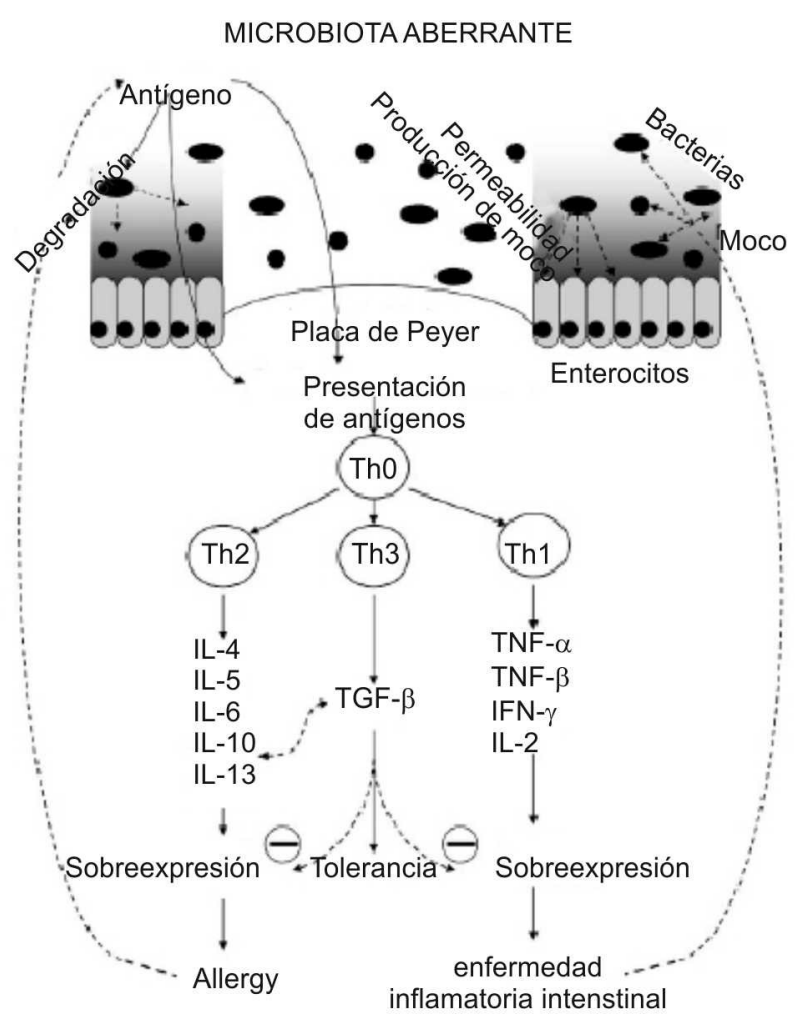

Figura 3. Potencial inmunomodulatorio de la flora intestinal. Tomada de: Rautava S, et al. The hygiene hypothesis of atopic disease-an extended version. J Pediatric Gastroenterol Nutrition 2004; 38: 378-88. 


\section{PARASITARIA}

Diferentes protozoos y helmintos varían notablemente en sus propiedades estructurales y bioquímicas, ciclos vitales y mecanismos patogénicos. Por lo tanto no es sorprendente que un sinnúmero de parásitos provoquen respuestas inmunitarias adaptativas distintas (10).

Paradójicamente, las infecciones por helmintos, que naturalmente provocan una fuerte respuesta Th2, parecen estar asociados con una baja prevalencia de sensibilización a enfermedad atópica $(1,13,16)$. Estos fueron los resultados arrojados en un estudio de Cooper y colaboradores, llevado a cabo en 2003 (13), en la provincia de Pichincha, Ecuador, en donde afirman que las geohelmintiasis, son las infecciones por helmintos más frecuentes en la población infantil, las cuales contribuyen a una baja prevalencia de enfermedades alérgicas.

Este fenómeno parece contradecir la desviación inmune Th1/Th2, propuesta en la hipótesis higienista. Se ha sugerido que la infección crónica parasitaria podría estar mediada por TGF-ß e IL-10, encargadas de restringir el daño producido por un continuo reto antigénico $(1,23)$.

\section{GENÉTICA}

El uso de endotoxina como un marcador potencial ante la exposición microbiana no sólo proporciona una herramienta epidemiológica útil, sino que también permite la identificación de una vía biológica bien definida, relacionada con las respuestas inmunológicas a tal exposición. Es posible dilucidar que los polimorfismos de los genes que codifican las proteínas involucradas en esta vía, puedan determinar, por lo menos en parte, la susceptibilidad individual a los efectos de la endotoxina.

En los laboratorios del Instituto de Ciencias Respiratorias de la Universidad de Arizona, Estados Unidos (6), se ha empezado un proceso de sondeo de polimorfismos de genes implicados con receptores de LPS. Han iniciado esta búsqueda con el gen CD14, el cual codifica para uno de los componentes principales del sistema de receptores, y hallaron una variación CT en la en la posición -159 de la región promotora del gen (CD14/-159). Este polimorfismo es muy frecuente en la población, con uno y medio de todos los cromosomas conteniendo uno u otro alelo (C o T) (6). Los portadores del alelo T en forma homocigota, mostraron tener niveles circulantes significativamente altos de SCD14, la forma soluble del receptor $(3,6)$. El grupo de investigaciones de esta universidad también halló que los homocigotos para el alelo T, tenían niveles séricos totales significativamente bajos de IgE, especialmente si eran positivos para el test dérmico de aeroalergenos locales $(3,6)$. Es más, portadores atópicos del alelo T mostraron un número de pruebas dérmicas significativamente bajos en comparación con los portadores del alelo C (6). Esto hace pensar que, por lo menos en algunas comunidades, existen polimorfismos que incrementan la expresión de CD14, y que ello podría estar relacionado con niveles bajos de IgE. Una posible explicación para estos hallazgos puede ser que una sensibilidad aumentada a la endotoxina y otros productos microbianos que interactúan con CD14 podrían incrementar las respuestas mediadas por IL-12, con un aumento concomitante de una respuesta tipo Th1 y un respectivo decaimiento de la respuesta Th2, evidenciada por los niveles bajos de $\lg E(3,6)$.

También se han estudiado polimorfismos del gen TLR4, pero no han tenido mayor impacto dado que parecen no estar asociados con el asma o un fenotipo alérgico (6).

\section{PREVENCIÓN}

Se ha visto que la infecciones por micobacterias son potentes inductores de una respuesta tipo Th1 $(1,6)$. Es por esto racional asumir que la exposición a una micobacteria como Mycobacterium tuberculosis o a BCG (Bacillus calmette-guerin), podría ser estímulo importante para una regulación a la baja de un fenotipo atópico, e incluso se ha planteado que puede haber una relación inversa entre la respuesta al test de tuberculina y el fenotipo alérgico $(6,14)$. Estudios recientes arrojan resultados poco alentadores en cuanto a la vacuna con BCG, dado que, si lo dicho anteriormente fuera cierto, se esperaría ver diferencias en la prevalencia de la enfermedad atópica entre países como Finlandia, donde prácticamente todo los niños son vacunados con BCG y en otros como Suecia, donde la vacuna BCG no es común (1).

Como se mencionó, la flora normal también asume un papel importante en la inmunomodulación ante un fenotipo atópico, y se ha mostrado que los probióticos tienen un potencial efecto de protección y tratamiento contra la enfermedad atópica (1). La administración de Lactobacillus GG $(1,3)$ después del nacimiento y durante la época de amamantamiento, ha mostrado una protección del niño ante el desarrollo de una enfermedad alérgica, de por lo menos cuatro años (1). En los niños con eccema atópico, la administración oral de Lactobacillus GG y Bifidobacterium lactis $B b-12$ se asoció con una mejoría significativa de la piel y una disminución en los marcadores sistémicos de inflamación $(1,15)$.

Además, en los niños con alergia a la leche de vaca y eccema atópico, se ha demostrado que el Lactobacillus GG alivia los síntomas y la inflamación intestinal asociada con este desorden (1). 
En nuestro concepto, aun más que tratamientos probióticos y vacunas, lo que más se ha relacionado con una prevención hacia un fenotipo alérgico es el hecho de tener un perro u otra mascota en la casa (3), al igual que el cuidado del niño durante el primer año de vida, lo cual no significa que éste no se pueda enfermar, ya que ello es un aspecto crucial en su desarrollo inmunológico, y la privación de este estado podría tener incluso más consecuencias que su no padecimiento.

\section{DISCUSIÓN}

La importancia de la hipótesis higienista radica en cómo participan los diferentes tipos de respuesta inmune en los procesos fisiopatológicos. Modulando estos tipos de respuesta se desencadenan condiciones favorables o desfavorables para el organismo. El reto inmunológico desde una temprana edad determina el desenvolvimiento del sistema inmune ante situaciones que comprometan a futuro al organismo. Como se anotó, ante diferentes microorganismos este proceso es diferente. En la mayoría de casos la respuesta que se desencadena no es benéfica, y por el contrario algunos de estos agentes desencadenaran una respuesta adversa que compromete al organismo. En algunos casos se desencadena una respuesta, en cierto modo beneficiosa para el organismo (por ejemplo helmintos que confieren inmunidad protectora en procesos alérgicos como el asma $(16,19)$.

Los retos inmunes a los que hoy en día está sujeto el mundo moderno, no liberan algunas de estas repuestas beneficiosas. Al contrario, la revisión de la evidencia sugiere que las etiologías multifactoriales como desórdenes atópicos, enfermedades autoinmunes y otros tipos de disfunción inmunológica, se han incrementado debido al tipo diferente y a la cantidad de exposición a retos microbianos que tendrán importancia en cuanto a las distintas respuestas del organismo en un futuro.

Aunque las respuestas ante los diferentes microorganismos sean variadas, el fin es el control de los procesos adversos, a lo cual se añade que se pueda buscar un fortalecimiento del sistema inmune, estimulando la producción de citoquinas moduladoras a fin de obtener una respuesta inmune protectora ante procesos alérgicos (Figura 4) (21).

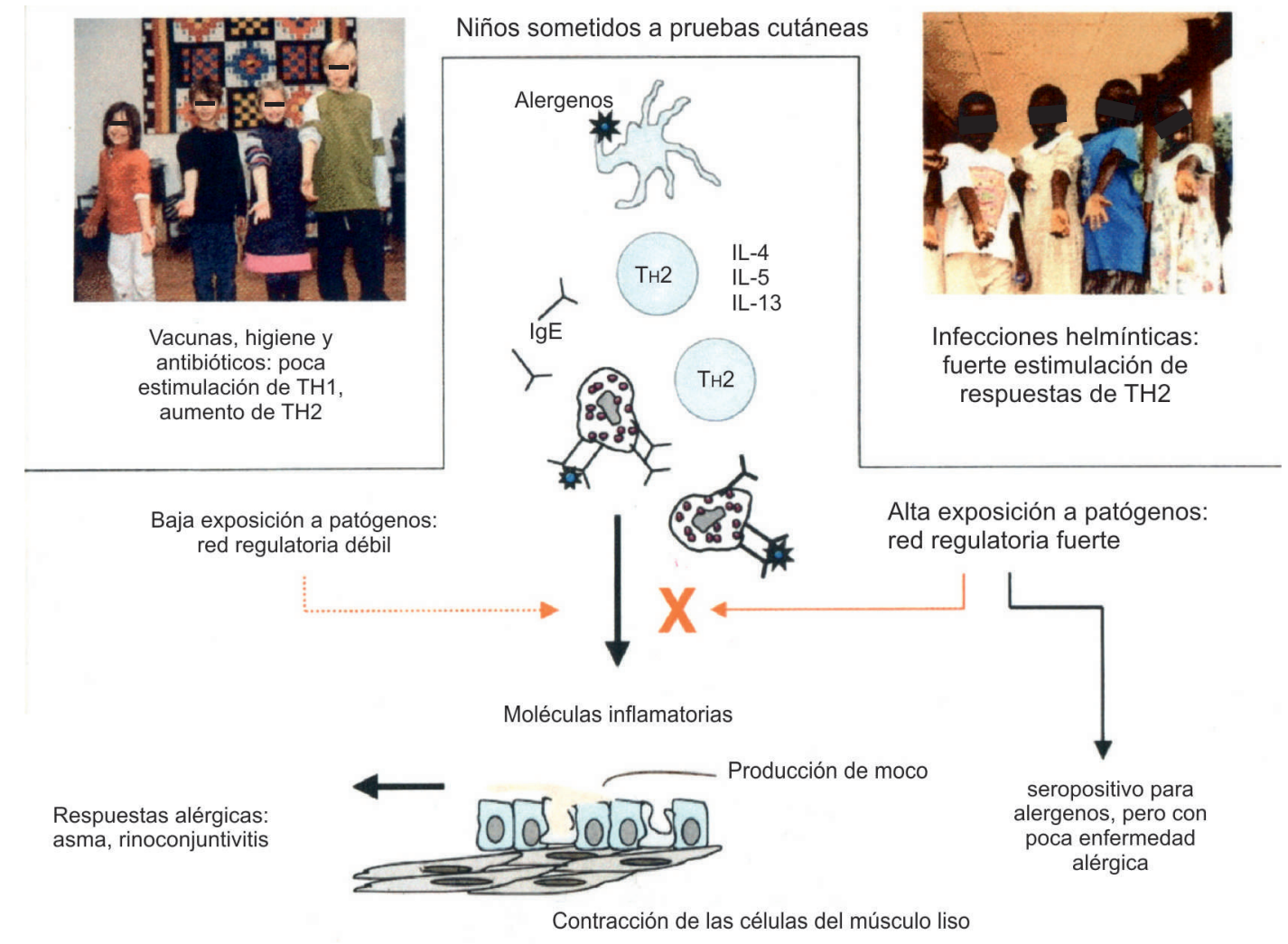

Figura 4. Ventajas de la infección en la prevención de enfermedades atópicas. Tomada de: Yazdanbakhsh M. Allergy, parasites, and the hygiene hypothesis. Science 2002;296 (5567): 490-4. 


\section{CONCLUSIONES}

La hipótesis higienista es un planteamiento relativamente nuevo (16 años) que hasta ahora empieza a tomar fuerza; no obstante, ha tenido grandes avances en los últimos años, hasta el punto de plantear una prevención contra el asma dentro de muchas otras enfermedades alérgicas.

A pesar de lo anterior se evidencian cuatro problemas que no sustentan la teoría:

1. La morbi-mortalidad por infecciones ha descendido. Enfermedades que antes eran mortales globalmente han disminuido su riesgo, pero en brotes reportados la infección cruzada no ha disminuido. Esto no prueba la hipótesis a menos que una infección específica pueda modular respuestas protectoras.

2. En familias pequeñas hay menos oportunidad de infecciones cruzadas puesto que en un grupo reducido es menor la cantidad de retos inmunológicos presentados. Pero esto prueba la hipótesis a menos que alguna infección no cause brotes o casos severos.

3. La urbanización ha disminuido el contacto con agentes ambientales, pero esto no constituye evidencia importante correlacionada con la etiología de la disfunción inmunológica. Se ha evidenciado que bacterias no patógenas pueden tener valor terapéutico para los desórdenes inmunes establecidos.

4. El creciente énfasis en la limpieza y la higiene no indica que el comportamiento y desarrollo de la infección se limiten por la práctica de higiene, puesto que la exposición a microorganismos no disminuye aunque haya limpieza (18).

El desarrollo progresivo de esta teoría arroja nuevas consideraciones sobre el progreso de las enfermedades actuales, dándonos bases para el conocimiento y mejoramiento de procesos patológicos prevenibles.

La evolución de la hipótesis higienista empezó con simples observaciones epidemiológicas planteadas por Strachan, a una integración con el mundo de la inmunología mediante el paradigma Th1/Th2 y más allá de esto, al mundo molecular de los receptores y las citoquinas, hasta encontrar bases genéticas para un posible fenotipo alérgico. Es muy alentador saber que gracias a las tecnologías disponibles hoy en día y al mantenimiento de la capacidad de asombro del hombre, se pueda avanzar en este y muchos otros campos, que hacen de los descubrimientos no más que un paso para el planteamiento de nuevos problemas.

\section{BIBLIOGRAFÍA}

1. Rautava S, Ruuskanen O, Ouwehand A, Salminen S, Isolauri E. The hygiene hypothesis of atopic disease-an extended version. J Pediatric Gastroenterol Nutrition 2004; 38: 378-88.

2. McGeady SJ. Immunocompetence and allergy. Pediatrics 2004; 113 (4): 1107-13I.

3. Eat dirt-The hygiene hypothesis and allergic diseases. New Eng J Med 2002; 347 (12): 930-1.

4. Strachan DP. Family size, infection and atopy: the first decade of the 'hygiene hypothesis'. Thorax 2000 55: 2-10.

5. Strachan DP. Hay fever, hygiene, and household size. British Med J 1989; 299: 1259-60.

6. Martinez FD. The coming-of-age of the hygiene hypothesis. The Respiratory Sciences Center 2001; 2: 129-32.

7. Von Mutius E, Braun-Fahrlander C, Schierl R, Riedler J, Ehlermann S, Maisch S, et al. Exposure to endotoxin or other bacterial components might protect against the development of atopy. Clinical \& Experimental Allergy 2000; 30: 1230-34.

8. Gelfand EW. The hygiene hypothesis revisited: pros and cons. Medscape 2003.

9. Murray PR, Rosenthal KS, Kobayanshi GS, Pfaller MA. Microbiología Médica. Cap. 3-Morfología sintesis y estructura de la pared celular de las bacterias-. 4ª . edición. España: Editorial Elsevier, S.A.; 2002.

10. Abbas, Lichtman, Pober. Inmunología celular y molecular. Cap. 15. Inmunidad frente a los microorganismos. $4^{\mathrm{a}}$. edición. Editorial Mc Graw Hill Interamericana; 2002.

11. Botero B, Restrepo M. Parasitosis humanas. Cap.16. Enfermedades causadas por artrópodos. $4^{a}$ edición. Medellín: Editorial Corporación para Investigaciones Biológicas. Colombia; 2003.

12. Chaouat $\mathrm{G}$. Innately moving away from the Th1/Th2 paradigm in pregnancy. Clinical \& Experimental Immunology 2003; 131 (3): 393-65.

13. Cooper PJ, Chico ME, Rodríguez LC, Ordónez M, Strachan D, Griffin GE, Nutman TB. Reduced risk of atopy among school-age children infected with geohelminth parasites in a rural area of the tropics. J Allergy and Clinical Inmunology 2003; 111 (5): 995-1000.

14. Shirakawa T, Enomoto T, Shimazu S, Hopkin JM. The inverse association between tuberculin responses and atopic disorder. Science 1997; 275: 77-79.

15. Majamaa $\mathrm{H}$, Isolauri E. Probiotics: a novel approach in the management of food allergy. J Allergy Clin Inmunol 1997; 99: 179-85.

16. Wickelgren I. Can worms tame the immune system? Science 2004; 305.

17. Hill AB. The environment and disease - association or causation? Proc Royal Soc Med 1965; 58: 295-300.

18. Stanwell-Smith R. The hygiene hypothesis and implications for home hygiene. Italy International Scientific Forum on Home Hygiene (IFH) Next Health Srl, P.le Türr Milano, 2004: 5-20149.

19. Cooper PJ. Can intestinal helminth infections (geohelminths) affect the development and expression of asthma and allergic disease? Clinical \& Experimental Immunology 2002; 128 (3): 398.

20. Capron A. Helminth infections and allergic diseases: from the th2 paradigm to regulatory networks. Parasite Allergy, Part I. Clinical Reviews in Allergy \& Immunology 2004; 26 (1): 25-34.

21. Maizels RM. Regulation of allergy and autoimmunity in helminth infection. Clinical Reviews in Allergy \& Immunology 2003; 26.

22. Yazdanbakhsh M. Allergy, parasites, and the hygiene hypothesis. Science. 2002; 296 (5567): 490-4.

23. Yazdanbakhsh M. Parasites and the hygiene hypothesis: regulating the immune system? Parasite Allergy, Part I. Clinical Reviews in Allergy \& Immunology. 2004; 26 (1): 15-24. 